DOI: $10.1515 / j b c r-2015-0170$

Case Report

\title{
EPIDERMOID CYST OF POSTERIOR CRANIAL FOSSA ASSOCIATED WITH CONGENITAL DERMAL SINUS TRACT - A CASE REPORT AND REVIEW OF THE LITERATUREDRINKING
}

\author{
Doroteya V. Malinova, \\ Penka L. Kolova, \\ Radoslav I. Georgiev ${ }^{1}$
}

\section{Department of General and Clinical pathology,}

Forensic Medicine and Deontology,

Medical Faculty,

Medical University, Varna

${ }^{1}$ Department of Imaging

Diagnostics and Radiotherapy,

Medical Faculty,

Medical University, Varna

\section{Corresponding Author:}

Doroteya V. Malinova

Department of General and Clinical pathology,

Forensic Medicine and Deontology

Medical University Prof. Dr. Paraskev

Stoyanov

55, Marin Drinov Str.

Varna, 9002

e-mail:dmalinova@gmail.com

Received: November 01, 2014

Revision received: May 29, 2015

Accepted: December 01, 2015

\section{Summary}

Epidermoid cysts are benign lesions composed of ectodermal structures. They account for less than $2 \%$ of primary intracerebral tumors. They can be present at birth (congenital cysts), or can be acquired cysts (after surgery or trauma). Some cysts are asymptomatic but depending on their location, they may cause symptoms such as headache, vertigo, seizures, focal deficits, increased intracranial pressure. The major differential diagnosis of epidermoid cysts are dermoid cyst, any cystic neoplasm, craniopharyngioma, arachnoid cyst. A 39-year-old female patient with complaints of headache, vertigo, nausea and vomiting was admitted to the hospital. Radiological data suggested intracranial tumor in fossa posterior. Craniotomy was performed and the biopsy specimen demonstrated the mass lesion to be an epidermoid cyst of the intracranial dermal sinus tract. Intracranial cystic-appearing masses can be problematic for both radiologists and physicians. Important characteristics demonstrated by computed tomography scans and classical magnetic resonance imaging sequences are significant for the accurate diagnosis, but the imaging appearances of intracranial cystic lesions are sometimes nonspecific, and the diagnosis is usually established by histological examination.

Key words: epidermoid cyst, differential diagnosis, intracranial tumor

\footnotetext{
Introduction

Epidermoid cysts are benign lesions composed of ectodermal structures. They account for less than $2 \%$ of primary intracerebral tumors. They can be present at birth (congenital cysts) or can be acquired cysts (after surgery or trauma). Usually these cysts are located in the cerebellopontine angle cystern (about $50 \%$ ), but they also arise in sellar and parasellar regions, the fourth ventricle, rhomboid fossa, corpus callosum, and the pineal gland $[1,2]$. Some cysts are asymptomatic but depending on their location, they may cause symptoms such as headache, vertigo,
} 
seizures, cranial neuropathy, increased intracranial pressure. The major differential diagnosis of epidermoid cysts are dermoid cyst, any cystic neoplasm, craniopharyngioma, arachnoid cyst [3].

\section{Clinical case}

A 39-year-old female patient with complaints of headache, vertigo, nausea and vomiting was admitted to the hospital. She did not sustain any injury to the occipital region at that time. Magnetic resonance imaging (MRI) of the brain (Figure 1) revealed a well-demarcated mass in the region of the posterior cranial fossa - strongly hypointense on sagital view and axial view. The fourth ventricle was normal in shape. There was obstructive hydrocephalus and raised intracranial pressure. Computed tomography of the brain
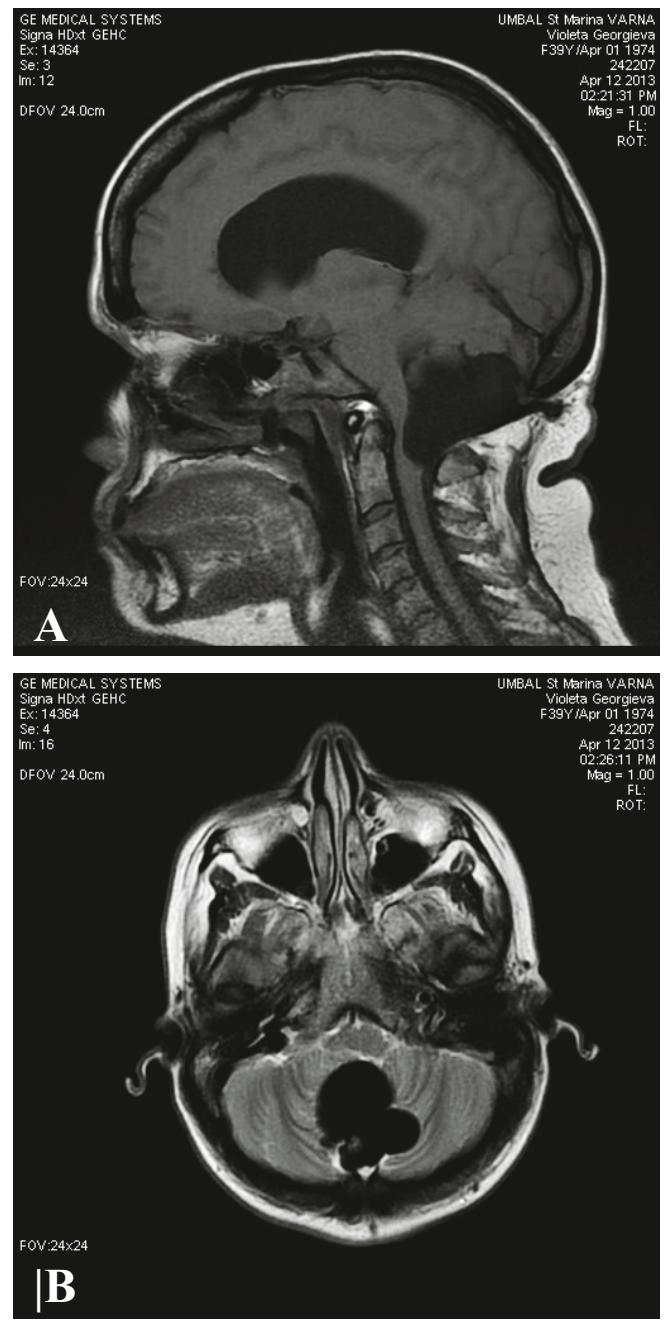

Figure 1. MRI of the brain. Defined lesion in the region of the posterior cranial fossa - strongly hypointense on saggital view (a) and axial view (b) showed hyperdense mass in the same region (Figure 2). A provisional diagnosis of dermoid cyst with a sinus tract was made. Other possibilities like epidermoid cyst or cystic neoplasm were also considered. She underwent craniectomy and excision of the cyst. On gross examination the cyst was round, thin-walled, and pearly-white. Histopathological examination of the excised cyst revealed a thin fibro-collagenous wall lined by stratified squamous epithelium containing focal areas of bone and calcifications (Figure 3, 4, 5). Adnexal structures including sebaceous glands, sweat glands and hair follicles were not found in the wall of the cyst. The final diagnosis was epidermoid cysts of intracranial dermal sinus tract.



Figure 2. CT of the brain (bone window).

Hyperdense lesion with dermal sinus tract in the posterior cranial fossa

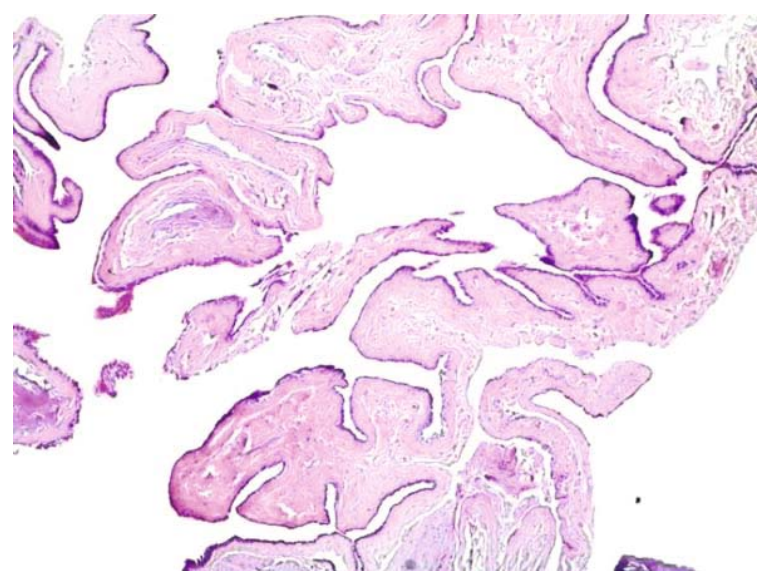

Figure 3. Thin fibro-collagenous wall of the cyst lined by stratified squamous epithelium. There are no hair follicles, sebaceous and sweat glands in the wall (hematoxylin and eosin stain, 20x10) 


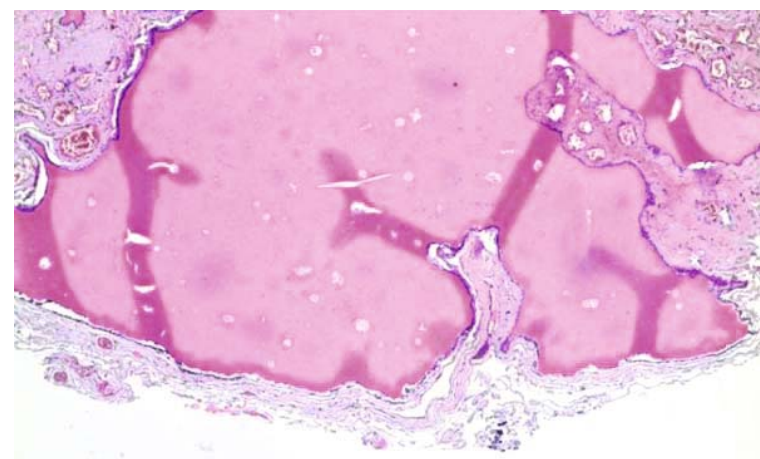

$[4,5,6]$.

Dermoid cysts are inclusion cysts composed of ectodermal structures. They are rare, accounting for approximately $0.04-0.6 \%$ of intracranial tumors $[7,8]$ and are thought to arise as a result of 'incomplete dysjunction' during gestation. In $60-80 \%$ of the cases, the residual tracts are associated with an inclusion tumor [9]. Dermoid cysts are well-defined and lined by stratified squamous epithelium. Usually they enlarge slowly and accumulate thick, yellowish to viscous greenish-brown material that consists of sebaceous gland secretions, whorls of hair, desquamated epithelium, fat and oil [10]. The presence of adnexal elements in the cyst wall is a

Figure 4. Areas of bone in the cyst surrounded by fibrous tussie and blood vessels (hematoxylin and eosin stain, 20x10)

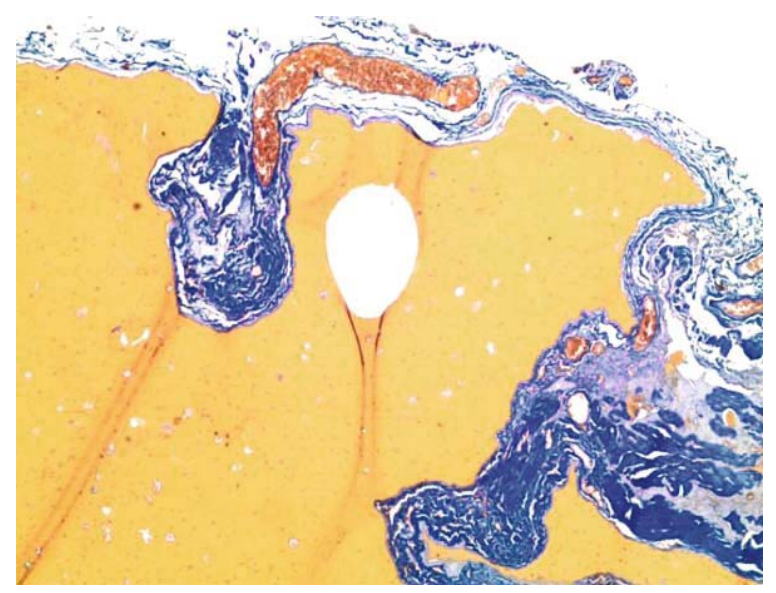

Figure 5. Areas of bone in the cyst surrounded by fibrous tussie and blood vessels, collagen is in blue, bone is in yellow (Azan stain, 20x10)

\section{Discussion}

Epidermoid cysts are benign cysts lined by keratinized stratified squamous epithelium and lacking skin adnexa that can occur anywhere along the neuriaxis. They rarely undergo malignant degeneration. Grossly these lesions have pearly appearance. Cholesterol content and cellular debris decrease the density of epidermoid cysts on $\mathrm{CT}$, so the latter can look similar in density to cerebrospinal fluid (CSF), and resemble an arachnoid cyst. Calcium deposits and bone areas are rare. Hyperdense appearance of an epidermoid cyst is extraordinary and is due to high protein content or haemorrhages. Findings on CT are similar to those on MRI, and often it is difficult to distinguish an epidermoid characteristic feature of dermoid cysts and distinguishes them from epidermoid cysts. Dermoid cysts have a characteristic nonhomogenous appearance on imaging due to its contents. They appear hypodense on CT scan. Calcifications are common. On magnetic resonance imaging, the fat content is seen strongly hyperintense. Occasionally, hypointense curve-like elements may be seen in the cyst when hair is present [10-12].

Arachnoid cysts contain CSF and arise in the subarachnoid space. Most of these cysts are sporadic, but they can be also congenital - they are often found in mucopolysaccharidoses. Researchers believe arachnoid cysts form as a result from congenital tearing of the arachnoid membrane with following accumulation of CSF. The wall of these cysts is composed of connective tissue and is lined by meningothelial cells. The most common site of involvement $(50-60 \%)$ is the middle cranial fossa. The cysts are welldefined, resembling CSF at CT scans and MRI. $[2,6]$.

Cystic neoplasms should also be mentioned in differential diagnosis of intracranial cystic lesions. They include pilocytic astrocytoma, craniopharyngioma, ganglioglioma, hemangioblastoma. Pilocytic astrocytoma is the most common neoplasm in the central nervous system in children. Pilocytic means hair-like, due to long processes of the tumor cells observed on histologic examination [13].CT and MRI scans show a well-defined mass with an associated macrocyst. The nodular part of the tumor is usually contrast enhancing [14]. Craniopharyngioma is an uncommon, usually suprasellar tumor, which originates from epithelial remnants of Rathke's pouch. This tumor may undergo cystic degeneration. Histologic appearance of craniopharyngioma is 
typical: the tumor consists of nests of squamous epithelium, and peripheral cells show nuclear palisading. Papillary structures and calcium deposits are common. The most specific radiologic finding is calcified cyst in the (supra) sellar region [15]. Hemangioblastomas are benign vascular neoplasms, usually found in the posterior cranial fossa. Cerebral angiography of patients with hemangioblastoma reveals a highly vascular tumor blush [16]. Gangliogliomas are variable in appearance on CT and MRI. Cystic neoplasms are contrast enhancing and have surrounding edema.

Intracranial cystic-appearing masses can be problematic for both radiologists and physicians. Important characteristics demonstrated by computed tomography scans and classical magnetic resonance imaging sequences are significant for the accurate diagnosis. However, the imaging appearances of intracranial cystic lesions are sometimes non-specific. Thus, the diagnosis is usually established by histological examination.

\section{Reference}

1. Chen CY, Wong JS, Hsieh SC, Chu JS, Chan WP. Intracranial epidermoid cyst with hemorrhage: MR imaging findings. AJNR Am J Neuroradiol. 2006;27(2):427-9.

2. Lantos PL, Louis DN, Kleihues P. Tumors of the nervous system. In: Graham DI, Lantos PL, editors. Greenfield's Neuropathology. 7th edition. London: Arnold; 2002.p. 964-70.

3. Ropper AH, Samuels MA, editors. Intracranial neoplasms and paraneoplastic disorders. In: Adams and Victor's Principles of Neurology. 9th edition. New York, NY: Mc Graw Hill; 2009. p. 644.

4. Burger PC, Scheithauer BW, editors. Benign cystic lesions. In: Tumors of the central nervous system. Atlas of Tumor Pathology. Book 7. Washington, DC: Armed Forces Institute of Pathology, American Registry of Pathology Press; 2007.p. 471-90.
5. Goel A, Shah A. Lateral supracerebellar transtentorial approach to a middle fossa epidermoid tumor. J Clin Neurosci. 2010;17(3):372-3.

6. Osborn AG, Preece MT. Intracranial cysts: radiologic-pathologic correlation and imaging approach. Radiology. 2006;239(3):650-64.

7. Liu JK, Gottfried ON, Salzman KL, Schmidt RH, Couldwell WT. Ruptured intracranial dermoid cysts: Clinical, radiographic, and surgical features. Neurosurgery. 2008;62:377-84.

8. Diyora B, Nayak N, Kale D, Kamble H, Sharma A. Frontal intraparenchymal "White epidermoid cyst": A rare occurrence. J Neurosci Rural Pract. 2010;1(2):125-7.

9. Higashi S, Takinami K, Yamashita J. Occipital dermal sinus associated with dermoid cyst in the fourth ventricle. AJNR Am J Neuroradiol. 1995;16(4 Suppl):945-8.

10. Canbaz B, Kemerdere R, Ocal E, Tanriverdi T. Intracranial dermoid cyst mimicking a giant thrombosed aneurysm. Neurol India. 2004;52(4):524-5.

11. Bladowska J, Bednarek-Tupikowska G, Biel A, Sasiadek M. Colloid cyst of the pituitary gland: case report and literature review. Pol J Radiol. 2010 Apr;75(2):88-93.

12. Brown JY, Morokoff AP, Mitchell PJ, Gonzales MF. Unusual imaging appearance of an intracranial dermoid cyst. AJNR Am J Neuroradiol. 2001;22(10):1970-2.

13. Kestle J, Townsend JJ, Brockmeyer DL, Walker ML. Juvenile pilocytic astrocytoma of the brainstem in children. J Neurosurg. 2004;101(1 Suppl):1-6.

14. Shankar JJ, Woulfe J, Silva VD, Nguyen TB. Evaluation of perfusion $\mathrm{CT}$ in grading and prognostication of high-grade gliomas at diagnosis: a pilot study. AJR Am J Roentgenol. 2013;200(5):W504-9.

15. Stamm AC, Vellutini E, Balsalobre L. Craniopharyngioma. Otolaryngol Clin North Am. 2011;44(4):937-52.

16. Gonzales MF. Classification and pathogenesis of brain tumors. In: Kaye AH, Laws ER, editors. Brain Tumors. $1^{\text {st }}$ ed. New York, NY: Churchill Livingstone; 1995.p. 31-45. 